\title{
Neurological diseases in pregnancy
}

\author{
${ }^{1} \mathrm{D}$ Kevat, ${ }^{2} \mathrm{~L}$ Mackillop \\ ${ }^{1}$ Honorary Specialist Registrar, Oxford University Hospitals NHS Trust, Oxford, UK and PhD candidate, School of Public Health, Monash \\ University, Melbourne, Australia; ${ }^{2}$ Consultant Obstetric Physician, Oxford University Hospitals NHS Trust, Oxford, UK
}

This review is based in part on a presentation given by Dr Mackillop at the Neurology Symposium on 4 October 2012 at the Royal College of Physicians of Edinburgh

\begin{abstract}
Neurological diseases are a major cause of morbidity and mortality in pregnancy. The management of multiple sclerosis, epilepsy, myasthenia gravis, certain neuropathies and headache in pregnancy is described; the potentially life-threatening conditions of stroke and eclampsia are also discussed. Management of most neurological conditions is similar to outside of pregnancy, but special consideration should be given to delivery plans and the safety of medications antenatally and during breastfeeding. Pre-pregnancy counselling, regular review and effective communication among a multi-disciplinary team are key to optimising management and outcomes.
\end{abstract}

\author{
Correspondence to L Mackillop \\ Women's Centre, \\ John Radcliffe Hospital \\ Headley Way, \\ Oxford \\ OX3 9DU, UK
}

tel. $+44(0) 186555615$

e-mail lucy.mackillop@ouh.nhs.uk

KEYWORDS Pregnancy, neurology, multiple sclerosis, epilepsy, headache

DECLARATION OF INTERESTS No conflicts of interest declared.

\section{PHYSIOLOGICAL CHANGES IN PREGNANCY}

A brief summary of the physiological changes helps contextualise the pathogenesis, differential diagnosis and management options for neurological conditions in pregnant women. These changes are designed to optimise conditions for the feto-placental unit, and potentially reduce risks for the mother at the time of delivery.

Cardiac output rises by $25 \%$ to $50 \%$ in singleton pregnancies through both increased heart rate and stroke volume, peaking at the beginning of the third trimester. Even greater increases occur in multiple pregnancies.' As systemic vascular resistance decreases during pregnancy, blood pressure is usually lower until the third trimester when the increased circulating volume and cardiac output increases it to near prepregnancy levels. ${ }^{2}$ Such variations of blood pressure and cardiac output are important when considering the threshold for treatment of hypertension, the risk of stroke and the diagnostic criteria for pre-eclampsia, as well as the management of rarer conditions such as known arteriovenous malformations.

In addition to the commonly found iron deficiency anaemia, the 'anaemia of pregnancy' consists of a marked increase in total red blood cell mass and a proportionally greater increase in plasma volume. Total blood volume increases by approximately I.5 L. Driven by rises in levels of factor VIII, IX, $X$ and fibrinogen ${ }^{3}$ there is an overall shift to a pro-coagulant state with an increasing risk of thrombus formation and stroke. Evidence suggests that changes in cytokine levels and diminished cytotoxic immune response contribute to fewer flare or relapses of autoimmune diseases, such as rheumatoid arthritis or multiple sclerosis. ${ }^{4}$
The decrease in albumin concentration, increase in total body water and glomerular filtration rate $(+50 \%)$ and changes in hepatic P450 system activity can greatly affect the pharmacokinetics of drugs, ${ }^{5}$ including anti-epileptic and thromboprophylactic medications. Other factors that can affect drug metabolism include nausea and vomiting (often worst in the first trimester) and longer gastrointestinal transit times.

\section{MULTIPLE SCLEROSIS}

The peak incidence of multiple sclerosis (MS) occurs in women aged 15 to 45 , child-bearing age. Latitudedependent, ${ }^{6}$ the disease has a relatively high prevalence in

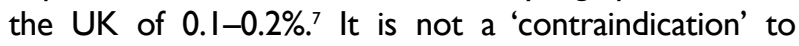
pregnancy, and in most cases, pregnancy has little or no deleterious effect on the condition and vice versa. Indeed, overall relapse rates for MS are lower during pregnancy, particularly during the third trimester. This is likely related to decreases in cell-mediated immunity, though a variety of immune system changes in pregnancy may also play a role, including an increased production of tolerancepromoting signalling molecules and CD4 interferon- $\gamma$. However, in the first three months post-partum, risk of relapse is increased with approximately $30 \%$ of women experiencing recurrence. ${ }^{8}$ The risk normalises after ten months, with no strong evidence to suggest overall disease progression or prognosis is changed. Given the high risk of relapse after delivery, (Figure I) planning to maximise social supports in this period is worthwhile.

The mode of delivery for women with MS should be based on obstetric factors. Similarly, the full choice of anaesthetic options for delivery should be available to almost all women with MS. It is important therefore to ensure anaesthetic assessment has taken place prior to onset of labour so these options are fully discussed with the patient. 


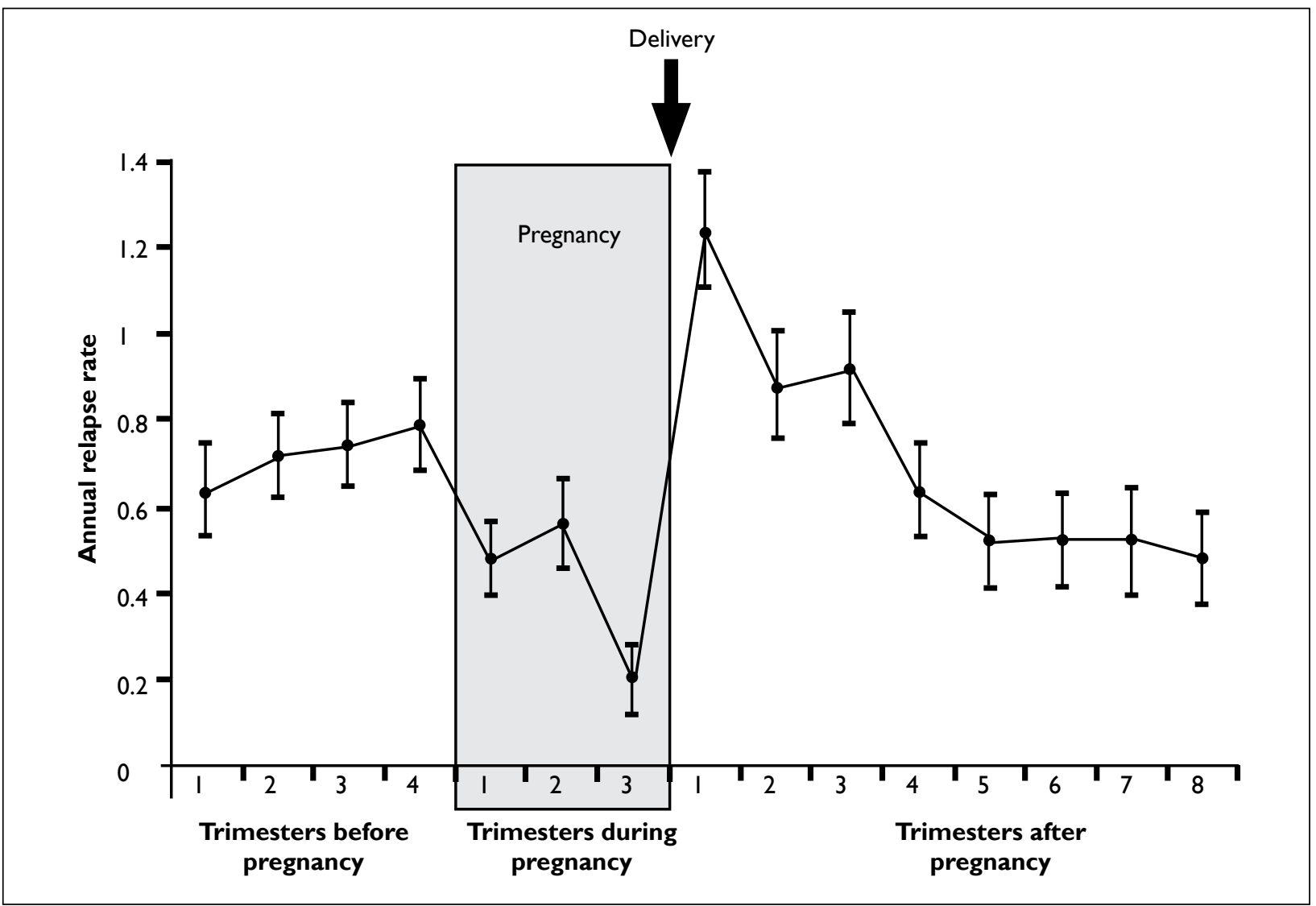

FIGURE I Risk of relapse of multiple sclerosis. ${ }^{8}$

There are concerns around the treatment of relapses during pregnancy should they occur. None of the current MS-specific drugs are approved for use during pregnancy in the US or the UK. However, no significant harm has been established. Glatiramer acetate has the most reassuring data based on animal testing models (FDA Category $B$ ) and a small case series. ${ }^{9} A$ recent systematic review (which included Canadian population database information) did not show an increased risk of adverse outcomes with natalizumab. Interferon beta was associated with premature birth. ${ }^{10}$ Glucocorticoids, usually in pulse dosing, can be prescribed, though use in the first trimester (where organogenesis occurs) is best avoided. Intravenous immunoglobulin (IVIG) may be used throughout pregnancy, though the usual risks of using a pooled blood product apply. A higher loading dose of $60 \mathrm{~g}$ (over three days) provides no extra benefit compared to 10 g; subsequent infusions can be four-weekly and reduce the risk of postpartum relapse." Progestin and estradiol are currently being trialled for the same purpose. ${ }^{2}$ Breastfeeding has not been consistently shown to be protective of a relapse of $M S$ in the postnatal period. As there are no definitive data on whether disease-modifying drugs such as glatiramer, used to treat MS, enter breast milk, breastfeeding is considered a contraindication to treatment with these agents. In cases of relapse, steroids or disease-modifying IVIG can be used, or breastfeeding ceased and diseasemodifying drugs (re-)commenced.

\section{MYASTHENIA GRAVIS}

Myasthenia gravis (MG) is twice as likely to affect women and onset is usually between the ages of 20 and 45 . The lifetime prevalence of the disease in the UK is $0.04 \% .{ }^{13} \mathrm{It}$ is caused by polyclonal immunoglobulin $\mathrm{G}(\lg \mathrm{G})$ antibodies directed against the nicotinic acetylcholine receptor of the skeletal muscles resulting in classic fatigable weakness, ptosis, diplopia, dysphagia, dysarthria and, in severe cases, respiratory muscle weakness. It is associated with thyroid disease and thymoma. Women requiring treatment may be taking anticholinesterases such as neostigmine and pyridostigmine, which inhibit breakdown of the neurotransmitter. While placental transfer is likely, there has been no significant evidence of adverse fetal outcomes among pregnant women taking these medications. Many women with MG will require management aimed at broad immune system dampening including IVIg, steroids, steroid-sparing agents (e.g. azathioprine, methotrexate, mycophenylate), plasmapheresis and/or thymectomy. Methotrexate is absolutely contraindicated in pregnancy and mycophenolate is teratogenic and should be avoided. More than $40 \%$ of women experience exacerbations of MG during pregnancy or in the post-partum period, where symptoms can be particularly sudden and severe. The risk of exacerbation is lower in women who have undergone a thymectomy. Approximately $30 \%$ of women will experience no change in symptomatology, with the 
remainder experiencing improvement, particularly in the third trimester. ${ }^{14}$ The course of the disease can vary in different pregnancies for the same individual.

Myasthenia gravis can cause a number of adverse effects on delivery; it has been associated with preterm delivery, protracted and complicated labour and increased rates of caesarean section. ${ }^{15,16}$ Women with MG may tire in particular in the second stage of labour, which requires repeated striated muscle contraction, and may need an instrumental delivery and sometimes a caesarean section. Epidural anaesthesia is permissible, but expert anaesthetic input is advised in planning and drug selection given the atypical pharmacokinetics and potential risk of a druginduced MG crisis. Beta blockers, aminoglycosides (such as gentamicin), and opioids may increase weakness. Depolarising and non-depolarising muscle relaxants can be administered in MG but at smaller doses - nondepolarising muscle relaxant (e.g.atracunium, vecuronium) dosing starts at a tenth of usual dose. Patients should be warned of the possible need for prolonged ventilation, and kept in a high dependency unit in case of postpartum worsening. ${ }^{17,18}$

One case report suggests that ergometrine can unmask MG; another indicates that betamethasone, given to mature the fetus' lungs, can precipitate a crisis. Magnesium sulphate, which is used in the treatment of pre-eclampsia and eclampsia, has also been noted to precipitate crisis. ${ }^{\mid 9-21}$

Women with MG should be counselled about the possible effects of the disease on the fetus. Passage of antibodies from mother to fetus in utero can cause inhibition of skeletal muscle, leading to contractures, pulmonary hypoplasia and polyhydramnios. Women with high antibody titres or who have had complications due to the condition in a previous pregnancy should be observed closely with regular ultrasound monitoring of total and diaphragmatic fetal movement. Persistently high titres may be lowered by plasmapheresis or other methods to reduce the likelihood of arthrogryposis multiplex congenita (AMC) and the considerable risk of perinatal mortality. The same mechanism can affect up to $20 \%$ of neonates. Diagnosis of neonatal MG is usually made within $\mathbf{4 8}$ hours, prompted by clinical suspicion of a 'floppy baby', poor feeding and, in severe cases, respiratory compromise. The condition can be managed expectantly or treated with anticholinergics, and usually resolves by eight weeks and often sooner. The risk of neonatal MG is higher in babies born to women with high antibody titres, and is probably lower in women who have undergone a thymectomy. ${ }^{22}$

\section{HEADACHE}

Headaches are a common cause of complaint for women. With the exception of cluster headaches, women are more affected by this condition than men (migraine $3: 1$, tension headache I.25:I). ${ }^{23}$ The most common types of headache are tension and migraine and evidence suggests they tend to improve during pregnancy, although the course can be unpredictable. Given the prevalence of these conditions, approximately one-third of all women will suffer symptom(s) during pregnancy, some for the first time. Knowledge of management techniques, including medication options in the context of the developing fetus and lactation, is thus useful for all doctors caring for pregnant women.

\section{Migraine}

The classic features of a migraine include visual or sensory symptoms prior to headache, nausea and/or vomiting and photophobia. 'Hard' neurological signs such as aphasia and hemianopia can also accompany migraine. Atypical migraines also exist, where there is minimal or no headache. An expectant woman who suffers from migraines is at a greater risk of hypertensive diseases associated with pregnancy. ${ }^{24,25}$ Migraine is considered to be a neurovascular disorder with mechanisms resulting in vasodilation, serotonin release, activation of $n$-methylD-aspartate (NMDA) receptors and stimulation of the peripheral and central nervous system. There is some evidence of hormonal influences on the process - the ratio of migraine incidence skews further towards women after puberty; some migraines are triggered by menstruation and exogenous estrogen has been used to successfully treat this group in research settings. ${ }^{26,27}$ Prospective studies indicate that for between $50 \%$ and $85 \%$ of migraine sufferers, symptoms will improve during pregnancy. ${ }^{28}$ Migraine without aura and menstrual migraine are more likely to improve than migraine with aura.

Migraine may be associated with the risk of pre-term delivery through co-morbid conditions (e.g. mood disorders) in a subgroup of patients. ${ }^{29}$ Importantly, a number of studies have established that migraine is associated with approximately double the risk of developing pregnancy-induced hypertension and preeclampsia; with obesity an additional risk factor. In addition, research supports a strong association with venous thrombosis, pulmonary embolism and stroke. ${ }^{30}$ There is also a well-known association between migraine with aura, cryptogenic (unexplained) stroke, and the presence of a patent foramen ovale. ${ }^{31}$ While the closure of the latter seems a 'biologically plausible' way of reducing the risk of stroke by abolishing the risk of paradoxical embolism, there is currently insufficient evidence to recommend this practice for primary or secondary prevention; randomised trials are underway.

\section{Tension headaches}

Tension type headaches are characterised by mild to moderate pressing pain that is usually bilateral. The discomfort is often described as a 'tightening' and can last anywhere from minutes to days. Evidence exists for a variety of pathogenic mechanisms including sensitisation of central nociceptors, the involvement of serotonin and 
nitrous oxide, and a precipitant role for involuntary movement of muscles (including teeth clenching). Comparatively little data is available on the course of tension headaches during pregnancy. Existing research supports the view that women are more likely to experience improvement (20-80\%) rather than deterioration and some will experience complete remission. Other women will experience no change, and a small minority will find symptoms worsen. ${ }^{28,32}$

\section{Diagnosis and management}

A thorough history and examination of the patient is essential for diagnosis and classification of headache in pregnancy and the post-partum period. The pattern of any associated symptoms should be carefully considered and investigated, as headache can be a secondary symptom of a number of dangerous conditions in pregnancy (Tables I and 2).

TABLE I Key examinations and investigations for headache in pregnancy

\begin{tabular}{ll|}
\hline - & Full neurological examination (including eye \\
- & examination) \\
- & Full blood count \\
- & Electrolytes, liver and renal function tests \\
- & Clotting profile \\
& Urinalysis and urine microscopy, culture and \\
- & Consitivity (MCS) \\
& resonance imaging (MRI) scan
\end{tabular}

TABLE 2 Causes of secondary headache in pregnancy

- Infection

- Pre-eclampsia

- Ischaemic or haemorraghic stroke

- Subarachnoid haemorrhage

- Idiopathic intracranial hypertension

- Dural puncture (post-anaesthetic procedure)

- Cerebral vein thrombosis

Imaging may be required and should be undertaken if a headache persists beyond 24 hours. The choice of modality of imaging depends on the indication and the availability in a particular institution. Although magnetic resonance imaging (MRI) is an attractive choice due to its lack of ionising radiation, a computed tomography (CT) of the head confers negligible radiation to the fetus. A CT is therefore usually the first-line investigation due to its availability, cost and speed compared to an MRI.

Idiopathic intracranial hypertension is becoming an increasingly common condition due to the rise in obesity in the obstetric population. Women with this condition should receive regular ophthalmic review during their pregnancy. Management options are similar to non- pregnant cases, including medications such as acetalozamide and thiazide diuretics. Repeated cerebrospinal fluid (CSF) drainage via lumbar punctures can be tried but there is little evidence to support this practice.

Non-pharmacologic therapies for headache management are worth trying, particularly in the pregnant population. Identification and elimination of triggers (caffeine, chocolate, smoking, dehydration, sleep patterns, insufficient exercise, psychological and physical stress) should be the starting point. Evidence supports the efficacy of biofeedback (particularly electromyography [EMG]), and acupuncture for the treatment of tension type headaches. ${ }^{33,34}$ Acupuncture has also been shown to be effective for the treatment of migraine. ${ }^{35}$

The aim of pharmacotherapy in the treatment of primary headache in pregnancy is to reduce the severity, duration and/or the frequency of attacks and their associated symptoms.

\section{Management of the acute attack}

Paracetamol should be tried as a first-line analgesic for headache. Codeine phosphate can be used as an adjunct to paracetamol to increase its analgesic effect. Aspirin (300 mg), acetaminophen, and non-steroidal antiinflammatories (NSAIDs) (e.g. ibuprofen, diclofenac) should be avoided if possible particularly in the third trimester (NSAIDs in particular have been linked to fetotoxic effects on the fetal kidneys and premature closure of the ductus arteriosus). Stronger opioids should only be used intermittently and avoided near full term because of the danger of maternal or fetal dependence and neonatal withdrawal. Non-steroidal anti-inflammatories are safe to take during breastfeeding, and short-term opioid use during this period is also considered safe. Aspirin may also be used intermittently during breastfeeding, though there is a theoretical risk of causing platelet dysfunction and Reye's syndrome.

Sumatriptan is a member of a class of more selective serotonin agonists with good efficacy for the treatment of migraine attacks. However approximately $15 \%$ of the drug passively crosses the placenta. There are registry data suggesting an association with lower birthweight, but none with congenital malformations. ${ }^{36} \mathrm{It}$ is suggested that the drug should be avoided if possible, but can be used intermittently if the patient is having infrequent but severe attacks. Little data are available about pizotifen, another drug which should be avoided in the first trimester during fetal organogenesis, but may be tried in the second and third trimester in those for whom other therapies have failed. Unfortunately, most evidence of drug safety in this area is the accumulation of anecdotal experience rather than trial data. Thus, while women can be informed that these medications are often used in pregnancy without adverse effects on the fetus, definitive reassurance is not possible. 


\section{Prophylaxis}

Anti-emetics such as metoclopramide should be prescribed with analgesia if required, as nausea and vomiting can be as distressing as pain for patients. Prophylaxis treatment can be considered in patients who have frequent attacks.Although data are conflicting, ${ }^{37}$ aspirin $(75 \mathrm{mg})$ can be effective in some patients. Doses of propranolol (the historic mainstay of preventative treatment) should be kept to the lowest effective dose in order to minimise the risk of fetal growth restriction. Noting the concomitant nature of depression and anxiety, medications targeted at these causes may also be effective. Frequent headaches prior to pregnancy is strongly associated with poor health and coping difficulties during pregnancy and the postnatal period. ${ }^{29}$

\section{EPILEPSY}

Epilepsy is a common condition, affecting $0.5 \%$ of the population. ${ }^{13}$ Most women are aware of their condition, providing an opportunity for pre-pregnancy counselling and drug optimisation in planned pregnancies. Epilepsy may be diagnosed for the first time during pregnancy, but careful exclusion of other diagnoses and organic causes of seizures must occur (Table 3 ).

TABLE 3 Possible causes of seizures in pregnancy

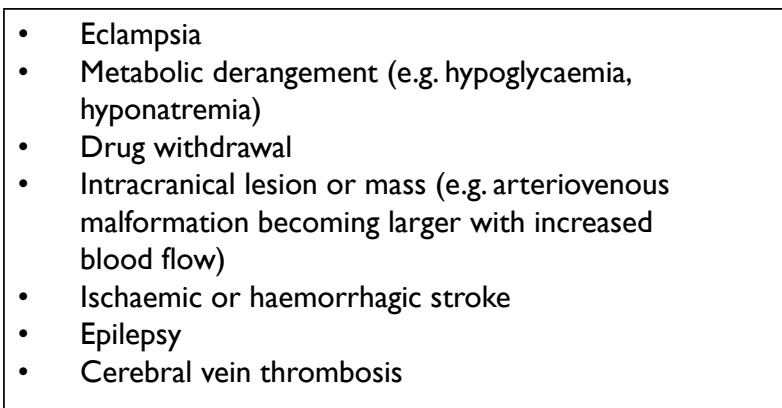

\section{Diagnosis}

Given the broad and potentially life-threatening causes of seizures in pregnancy, it is essential that a full patient history is gathered, a complete examination performed and any investigations are carried out as needed (Table 4).

TABLE 4 Key examinations and investigations for seizures in pregnancy

\begin{tabular}{|c|}
\hline 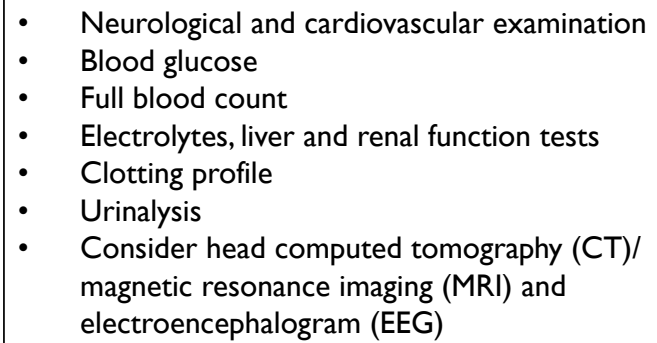 \\
\hline
\end{tabular}

\section{Epilepsy and pregnancy}

Two-thirds of women will have no change to the frequency of seizures during pregnancy, one in six will experience improvement, and one in six, deterioration. ${ }^{38}$ Those with poorly controlled epilepsy prior to pregnancy are more likely to experience deterioration in their condition. Epilepsy is associated with maternal deaths (0.5-I per $100,000$ pregnancies $)^{39}$ via aspiration or the disorder itself. Unexplained death (sudden unexplained death in epilepsy [SUDEP]) can also occur, but rates have not been noted to be different for non-pregnant women taking medications. There is a $2-4 \%$ chance of having a seizure peri-delivery. ${ }^{40}$ This is likely due to a combination of factors, including an increase in precipitants (tiredness, stress) and not taking or vomiting medication during labour.

Long episodes of seizure activity (including status epilepticus [SE]) can be harmful to both the fetus and mother but it is relatively rare, affecting less than $2 \%$ of pregnancies. ${ }^{38}$ There is no association between epilepsy and early delivery or increased risk of obstetric complications. Women who have significant seizures should deliver in a facility with on-site medical support but a history of epilepsy is not an indication for induction of labour or a caesarean section. ${ }^{41}$

A major and justifiable concern for women with epilepsy is the risk that anti-epileptic drugs (AEDs) will cause fetal malformation. Rates of major congenital malformation (MCM) are higher in women taking AEDs, with a greater risk of malformation for women taking sodium valproate alone (6\%), or on polytherapy (6\%), and particularly those on polytherapy regimes containing valproate (9\%). ${ }^{42}$ Most studies indicate that the overall risk of MCM for women on monotherapy (excluding valproate and topiramate) is approximately 3\% (Table 5). Exposure to AEDs has been associated with orofacial clefts, congenital heart disease, neural tube defects, dysmorphic facial features and delayed cognitive development.

\section{Management}

Pre-pregnancy counselling is an important but sometimes neglected area of medical practice. Many women with epilepsy will consider pregnancy at some point and thus a proactive conversation (e.g. at time of an annual review, contraceptive prescription or cervical smear result) asking patients to seek medical advice at the appropriate time is warranted. Women may stop taking AEDs without seeking medical advice because of concerns about malformations. While the risk of MCM is a real one, it must be weighed against the risks of increased seizure activity.

For most women, staying on the AEDs will be an appropriate course of action. Those on sodium valproate may consider changing to an AED with a lower MCM rate, or have their dose split (to three times a day) and ideally reduced to the minimum required for seizure 
TABLE 5 Rates of major congenital malformation in six different studies ${ }^{42}$

\begin{tabular}{|l|c|c|c|c|c|}
\hline & Valproate & $\begin{array}{l}\text { Carba- } \\
\text { mazepine }\end{array}$ & Lamotrigine & $\begin{array}{l}\text { Pheno- } \\
\text { barbital }\end{array}$ & Phenytoin \\
\hline $\begin{array}{l}\text { International Lamotrigine Pregnancy } \\
\text { Registry }\end{array}$ & - & & $35 / 1,558(2 \%)$ & & \\
\hline $\begin{array}{l}\text { Finnish Medical Birth Registry and drug } \\
\text { prescription databases }\end{array}$ & $28 / 263(11 \%)$ & $22 / 805(3 \%)$ & - & & $1 / 38(3 \%)$ \\
\hline Swedish Medical Birth Registry* & $29 / 619(5 \%)$ & $35 / 1,318(3 \%)$ & $26 / 867(3 \%)$ & & $8 / 119(7 \%)$ \\
\hline UK Epilepsy and Pregnancy Registry & $44 / 715(6 \%)$ & $20 / 900(2 \%)$ & $21 / 647(3 \%)$ & & $3 / 82(4 \%)$ \\
\hline $\begin{array}{l}\text { North American AED Pregnancy } \\
\text { Registry }\end{array}$ & $30 / 323(9 \%)$ & $31 / 1,033(3 \%)$ & $31 / 1,562(2 \%)$ & $11 / 199(6 \%)$ & $12 / 416(3 \%)$ \\
\hline $\begin{array}{l}\text { International Registry of Antiseptic } \\
\text { Drugs and Pregnancy (EURAP) }\end{array}$ & $98 / 1,010(10 \%)$ & $79 / 1,402(6 \%)$ & $37 / 1,280(3 \%)$ & $16 / 217(7 \%)$ & $6 / 103(6 \%)$ \\
\hline $\begin{array}{l}\text { Data are number with major congenital malformation/number exposed to antiepileptic drug monotherapy (\%). } \\
\text { "Källén K, University of Lund, Sweden. Personal communication. } \\
\text { AED= Anti-epileptic drug }\end{array}$ & & \\
\hline
\end{tabular}

control and less than I,200 mg total daily dose. If possible, those on polytherapy should have the number of drugs they are on reduced, but this may depend on their seizure history. All women should have baseline drug levels taken, be prescribed high-dose folic acid $(5 \mathrm{mg})$ preconceptually and for at least the first trimester, and be advised to avoid having baths or swimming alone. Screening for congenital malformation should be offered to all women on AEDs.

Women taking AEDs with minimal protein binding such as lamotrigine and carbamazepine may need to have drug doses increased, the former usually by $25 \%^{43}$ to $50 \%$ of the pre-pregnancy dose. This is to ensure therapeutic levels of free drug concentration in the context of increased plasma volume and hepatic and renal clearance. Other drugs may also need their doses adjusted because of the altered pharmacokinetics of pregnancy. With the exception of lamotrigine, usual practice is to be guided in dose increases by seizure symptomatology rather than drug levels. Women should be reassured that fetal exposure will remain at low levels despite dose increases.

Although little evidence supports the practice, women on enzyme-inducing drugs such as carbamazepine and phenytoin are often given oral vitamin $\mathrm{K}$ during the last month of pregnancy to reduce the risk of maternal haemorrhage at the time of delivery and to increase fetal levels of vitamin K-dependent clotting factors. Intramuscular vitamin $\mathrm{K}$ should be given to all neonates to reduce the risk of haemorraghic disease of the newborn which can be caused by insufficient vitamin K-depending clotting factors.

All AEDs should be taken up to and including during delivery. Peri-delivery seizures that are longer than 30 seconds should be terminated with a benzodiazepine. In delivery planning this should be documented, and drugs should be easily accessible. Women with a very high risk of seizures at this time can be managed with additional clonazepam, clobezam or phenytoin around the time of delivery.

After delivery, any AED drug dose increased over pregnancy should be decreased over the next one to four weeks. Although small amounts of most AEDs are expressed in breast milk, the overall benefits outweigh risks and women should be encouraged to breastfeed. Lamotrigine is measured in expressed breast milk at much higher levels and is not eliminated quickly in the newborn. Rarely, some babies may become excessively drowsy as a drug effect - feeding prior to ingesting medication should be tried as plasma drug levels will be at their lowest. Mothers and their partners should be informed of the risks and management techniques for seizures at this time. Babies should be bathed when the mother is accompanied by another person. Nappy and clothes changes should be done on the floor, and co-sleeping is discouraged. Sleep deprivation can trigger seizures and thus family members should be informed of the importance of placing the mother in the recovery position, preventing choking and be provided with seizure termination drugs if needed.

\section{ECLAMPSIA}

Pre-eclampsia is a dangerous disease confined to pregnancy, which occurs after 20 weeks gestation and has a diverse range of manifestations. The historical triad of hypertension, oedema and proteinuria are common, but modern diagnostic criteria are more sophisticated and do not require all of these to be present. ${ }^{44}$

Eclampsia is a tonic-clonic seizure associated with preeclampsia. Current research indicates that the seizure may result from cerebral vasospasm and/or hypertensive encephalopathy. The middle cerebral artery may not 
autoregulate a rising blood pressure affecting the parietal regions. Sympathetic control of the basilar arterial symptoms is poor, resulting in the supplied parietal and occipital areas being at risk of autoregulatory failure and being most affected by hypertension. ${ }^{45}$

Along with headache, visual disturbance is a common premonitory symptom. Cortical blindness is a rare but established complication associated with eclampsia, but fortunately resolves in some cases. More than a third of eclamptic seizures occur post-partum, necessitating continued vigilance after delivery. While the risks of eclampsia are higher in cases of severe pre-eclampsia, it is not the 'final' stage in a temporal sequence or the 'culmination' of worsening symptoms and signs. Indeed, two-thirds of women in the UK do not have established hypertension or proteinuria in the week prior to their first seizure. A fifth of women have a seizure outside of hospital. ${ }^{46}$ A first seizure after 20 weeks gestation should prompt consideration of eclampsia/preeclampsia as a diagnosis.

Eclampsia constitutes an obstetric emergency. Women should be transferred to an area of the ward which has sufficient medical and nursing care. Together with blood pressure control, intravenous magnesium sulphate should be commenced without delay. A loading dose of $4 \mathrm{~g}$ should be given followed by an infusion of $\mathrm{I} g$ per hour. If a further seizure occurs, a bolus of $2 \mathrm{~g}$ can be given and serum magnesium levels should be checked regularly - the therapeutic range is $2-4 \mathrm{mg} / \mathrm{L}$. The infusion is usually stopped 24 hours after delivery or post-partum seizure. Clinical judgement should be used in cases of antepartum or post-partum cerebral irritation - agitation, confusion, drowsiness, hyperreflexia and headache. Magnesium can be used for primary prophylaxis.As pre-eclampsia only begins to resolve after delivery of the placenta, plans to expedite this should be made. This should occur only after the mother's condition is stabilised with adequate blood pressure control, seizure prophylaxis and reversal of any coagulopathy. As in any high-risk situation, ongoing monitoring of the fetus and the mother's vital signs is required until the situation resolves. The mother should receive post-partum blood tests (full blood count, electrolytes, renal and liver function, clotting profile, electrolytes and urinalysis) to ensure results are trending towards improvement. Thromboprophylaxis is important for these high-risk patients.

\section{STROKE}

While ischaemic stroke is more common (5:1) outside pregnancy, haemorrhagic stroke is more likely during pregnancy. ${ }^{30,47}$ In addition to the usual vascular risk factors, a number of changes during pregnancy (Table 6) contribute to increased risks of stroke. The third trimester and postpartum period are the times of highest risk.
TABLE 6 Key factors contributing to an increased risk of stroke during pregnancy

\begin{tabular}{|l|l|}
\hline Haematologic & $\begin{array}{l}\text { A rise in the levels of factor VIII, IX, X } \\
\text { and fibrinogen and a decrease in the } \\
\text { levels of antithrombin and protein S }\end{array}$ \\
\hline Cardiac & $\begin{array}{l}\text { A large rise in cardiac output, increased } \\
\text { blood vessel distension, compromised } \\
\text { venous return, risk of hypertension } \\
\text { and vasospasm in hypertensive diseases } \\
\text { of pregnancy; a higher incidence of } \\
\text { arrhythmias }\end{array}$ \\
\hline Endocrine & $\begin{array}{l}\text { An increase in estrogen-mediated } \\
\text { cholesterol and the potential for } \\
\text { women in a diabetogenic state to } \\
\text { result in gestational diabetes }\end{array}$ \\
\hline Surgical & $\begin{array}{l}\text { A caesarean section or other surgery/ } \\
\text { procedures }\end{array}$ \\
\hline
\end{tabular}

Most estimates of the number of strokes associated with pregnancy place the risk between 4 and 40 per 100,000 pregnancies, with variation depending on country, diagnostic certainty (clinical signs vs imaging), ${ }^{48-50}$ whether the post-partum period has been included, and potential selection bias as suggested by hospital type. Recent US registry data have been at the lower end of this range but trending upward from 13 to 29 per 100,000 deliveries between 1994 and 2007.51 Recent UK data, collected using a different methodology estimated a rate of $\mathbf{I . 5}$ strokes per 100,000 deliveries, though the post-partum period was excluded in this study, and there was an acknowledged risk of a degree of under-ascertainment. ${ }^{50}$

Stroke is a rare event in pregnancy but can have a devastating impact on a woman's life, and her ability to care for her child. Post-stroke mortality has been found to be higher in pregnant compared to non-pregnant women, with an overall case fatality rate of $20 \%$ (50\% for haemorrhagic stroke). ${ }^{52}$

\section{Haemorrhagic stroke}

Hypertension is the single most important treatable risk factor for haemorrhagic stroke in pregnancy; progressively higher blood pressures are associated with increasing risk level. Blood pressure should be kept below 160/1 I0 $\mathrm{mm} \mathrm{Hg}$; measurements above this are a medical emergency in the obstetric population. Low dose aspirin $(<150 \mathrm{mg})$ as prescribed to reduce the risk of preclampsia is not associated with a significant increase in risk of haemorrhagic stroke. Women with known arteriovenous malformations should discuss their condition with a neurologist or neurosurgeon. Some studies suggest that the risk of rupture during pregnancy (approximately $3.5-5.8 \%$ ) is higher than the background risk though one small recent study recorded a rate of 8.1\%.53,54 There is an increased risk of bleeding in pregnancy with larger malformations and if there has been bleeding before. If a pregnancy is being planned then required procedures may be done before conception. 
Women who suffer a haemorrhagic stroke should be seen urgently by a neurologist and admitted to an acute stroke unit for multi-disciplinary care.

\section{Ischaemic stroke}

Some women will be at a higher risk of thrombotic or ischaemic stroke due to known factors such as previous unprovoked thrombosis, thrombophilias (in particular antiphospholipid antibody syndrome), or who have a mechanical heart valve. Comprehensive guidelines for assessing these risks as well as management recommendations are available. ${ }^{55}$ Management can include aspirin, prophylactic or therapeutic unfractionated heparin or low molecular weight heparin or warfarin throughout the entirety of the pregnancy, or a mixed regime to minimise the chance of warfarin embryopathy. Warfarin and heparin are considered safe for breastfeeding mothers. No significant data are available on the other antiplatelet agents such as clopidogrel for stroke prevention in pregnancy. The management of anticoagulation during delivery can be challenging and is beyond the scope of this paper but may be planned by elective delivery. Caesarean sections should be reserved for obstetric indications.

Recent evidence shows that only $20 \%$ of pregnant women in the UK who suffer a stroke in pregnancy are seen urgently by a neurologist and admitted to an acute stroke unit even though this has been demonstrated to improve outcomes..$^{50}$ There are a number of case reports of successful thrombolysis in acute stroke in pregnancy, but no high quality studies. There have also been reports of a number of intracranial haemorrhages in this population following lysis; the decision to thrombolyse or not is therefore extremely challenging. Aspirin should be prescribed to all pregnant women for secondary prevention of stroke.

\section{CEREBRAL VEIN AND SINUS THROMBOSIS}

Cerebral vein thrombosis occurs more commonly in pregnancy ( 11.6 per 100,000 deliveries) and is associated with high morbidity and mortality; ${ }^{56}$ in some developing countries the rate is reported to be more more than ten times higher due to infection, dehydration, anaemia, vegetarian diet and higher homocysteine levels. The diagnosis should be considered in any pregnant patient presenting with the signs or symptoms of stroke raised intracranial pressure, headache, photophobia, vomiting and/or fever. Pathogenesis likely involves the interaction between the hypercoagulable state of pregnancy and micro trauma to the endothelium of cerebral veins and sinuses. It is important to distinguish cases of pseudotumour cerebri where symptoms are secondary to raised intercranial pressure of unknown aetiology, as steroids may be used with good clinical effect in the latter condition. Suspected cerebral vein thrombosis should ideally be investigated by magnetic resonance imaging/venography (MRI/ $\mathrm{V})$. Management is by hydration and anticoagulation with heparin and appropriate symptomatic control.

\section{NEUROPATHIES}

There is a greater incidence of entrapment neuropathies during pregnancy. Carpal tunnel syndrome affects at least $2 \%$ of pregnant women ${ }^{57}$ and usually manifests as pain, numbness or parasthesia of the index and long fingers and adjacent surfaces of the thumb and ring finger. A recent systematic review identified a wide and higher incidence of the condition (up to $43 \%$ ) depending on diagnostic criteria. ${ }^{58} \mathrm{It}$ is precipitated by compression of the median nerve in the carpal tunnel of the wrist, and is treated with simple analgesia and/or wrist splints. Local steroid injections should be reserved for severely affected patients; most cases will resolve post-partum.

Post-partum dysfunction of nerves of the lumbosacral plexus can manifest in altered sensation and motor function in the legs - the most common lesion is of the peroneal nerve, causing foot drop. Short primigravidas, forceps delivery, narrow pelvis, large fetal head, and occipito-posterior position are risk factors. ${ }^{99}$ Prolonged squatting should be avoided to minimise pressure from the fibular head on the nerve. Management is with physiotherapy and orthotics/boots if needed.

Bell's palsy, a unlilateral lower motor lower palsy, may be more common in pregnancy, and affects between 0.02$0.05 \%$. of women..$^{60,61}$ Symptoms and prognosis are the same as outside pregnancy. If steroids are being considered, Ramsay Hunt syndrome should be excluded by ear examination. Prednisolone (which can be safely given in pregnancy) can speed recovery and reduce the severity of symptoms if instituted within $\mathbf{4 8}$ hours; more than $90 \%$ of cases will resolve spontaneously over a period of months. ${ }^{22}$

\section{CONCLUSION}

Neurological conditions are a significant source of morbidity and mortality in pregnancy. Pregnancy does constitute a 'special circumstance' partly due to altered physiology and the need to consider specific issues such as mode of delivery, anaesthesia, the second stage of labour and breastfeeding. However, most neurological conditions are managed in a similar manner to outside of pregnancy. Communication and planning, including prepregnancy counselling, are key to successful management. For this reason women should be managed by a multidisciplinary team consisting of a neurologist, obstetrician, anaesthetist, midwife and general practitioner,contributing to optimum outcomes for mother and baby. 


\section{REFERENCES}

I Kametas NA, McAuliffe F, Krampl E et al. Maternal cardiac function in twin pregnancy. Obstet Gynecol 2003; 102:806-15. http://dx.doi. org/10.1016/S0029-7844(03)00807-X

2 Duvekot JJ, Peeters LL. Maternal cardiovascular hemodynamic adaptation to pregnancy. Obstet Gynecol Surv 1994; 49:SI-14. http:// dx.doi.org/ I0.1097/00006254-1994 I201 I-00001

3 Brenner B. Haemostatic changes in pregnancy. Thromb Res 2004; I |4:409-14. http://dx.doi.org// 0.10 I6/j.thromres.2004.08.004

4 Saraste $M$, Vaisanen S, Alanen A et al. Clinical and immunologic evaluation of women with multiple sclerosis during and after pregnancy. Gend Med 2007; 4:45-55. http://dx.doi.org//0.1016/ SI550-8579(07)80008-8

5 Anderson GD. Pregnancy-induced changes in pharmacokinetics: a mechanistic-based approach. Clin Pharmacokinet 2005; 44:9891008. http://dx.doi.org//0.2I65/00003088-200544/00-0000 I

6 Ascherio A, Munger KL. Environmental risk factors for multiple sclerosis. Part I: the role of infection. Ann Neurol 2007; 61:288-99. http://dx.doi.org/10.1002/ana.21117

7 Pugliatti M, Rosati G, Carton $\mathrm{H}$ et al.The epidemiology of multiple sclerosis in Europe. Eur J Neurol 2006; 13:700-22. http://dx.doi. org/I0.IIII/j.|468-I33I.2006.0I342.x

8 Vukusic S, Hutchinson M, Hours M et al. Pregnancy and multiple sclerosis (the PRIMS study): clinical predictors of post-partum relapse. Brain 2004; I27:1353-60. http://dx.doi.org/I0.1093/brain/ awh 152

9 Salminen HJ, Leggett H, Boggild M. Glatiramer acetate exposure in pregnancy: preliminary safety and birth outcomes. J Neurol 2010; 257:2020-3. http://dx.doi.org/I0.1007/s004/5-010-5652-y

I0 Lu E, Wang BW, Guimond C et al. Disease-modifying drugs for multiple sclerosis in pregnancy: a systematic review. Neurology 2012; 79: I | 30-5. http://dx.doi.org/10.1212/WNL.0b0 I3e3182698c64

II Haas J, Hommes OR. A dose comparison study of IVIG in postpartum relapsing-remitting multiple sclerosis. Mult Scler 2007; | 3:900-8. http://dx.doi.org// 0.1 | 77//352458506075654

12 Vukusic S, lonescu I, El-Etr M et al. The Prevention of Post-Partum Relapses with Progestin and Estradiol in Multiple Sclerosis (POPART'MUS) trial: rationale, objectives and state of advancement.J Neurol Sci 2009;286: I I 4-8.http://dx.doi.org/I 0.1016/j.jns.2009.08.056

I3 MacDonald BK, Cockerell OC, Sander JW et al.The incidence and lifetime prevalence of neurological disorders in a prospective community-based study in the UK. Brain 2000; 123:665-76. http:// dx.doi.org/ I0.1093/brain/I23.4.665

14 Plauche WC. Myasthenia gravis in mothers and their newborns. Clin Obstet Gynecol I99I; 34:82-99. http://dx.doi.org/I0.1097/0000308I 199103000-000I2

15 Hoff JM, Daltveit AK, Gilhus NE. Myasthenia gravis: consequences for pregnancy, delivery, and the newborn. Neurology 2003;61:13626. http://dx.doi.org/I0.12I2/0I.WNL.0000082725.2I444.EC

16 Hoff JM, Daltveit AK, Gilhus NE. Asymptomatic myasthenia gravis influences pregnancy and birth. Eur J Neurol 2004; II:559-62. http://dx.doi.org/I0.I I I I/j. I 468-I33 I.2004.00900.x

17 Bashuk RG, Krendel DA. Myasthenia gravis presenting as weakness after magnesium administration. Muscle Nerve 1990; 13:708-12. http://dx.doi.org//0.1002/mus.880I30808

18 Catanzarite VA, McHargue AM, Sandberg EC et al. Respiratory arrest during therapy for premature labor in a patient with myasthenia gravis. Obstet Gynecol 1984; 64:819-22.

19 Ahmad S. Myasthenia gravis unmasked by ergonovine. Am Heart J 1991; |21:|851. http://dx.doi.org/10.1016/0002-8703(91)90070-X

20 Hoff JM, Daltveit AK, Gilhus NE. Myasthenia gravis in pregnancy and birth: identifying risk factors, optimising care. Eur J Neurol 2007; |4:38-43. http://dx.doi.org/I0. I I I I/j.| |468-|331.2006.0I538.x

2I Gambling DR, Douglas MJ, McKay RSF. Obstetric anesthesia and uncommon disorders. Cambridge: Cambridge University Press; 2008. http://dx.doi.org/I0.1017/CBO97805II544552

22 Dillon FX.Anesthesia issues in the perioperative management of myasthenia gravis. Semin Neurol 2004; 24:83-94. http://dx.doi. org/10.1055/s-2004-829587
23 Rasmussen BK, Jensen R, Schroll M et al. Epidemiology of headache in a general population: a prevalence study. J Clin Epidemiol 1991; 44:I |47-57. http://dx.doi.org//0.1016/0895-4356(9|)90|47-2

24 Scher Al, Terwindt GM, Picavet HS et al. Cardiovascular risk factors and migraine: the GEM population-based study. Neurology 2005; 64:6I4-20. http://dx.doi.org/I0.12 I2/0I.WNL.0000I5I857.43225.49

25 Facchinetti F,Allais G, Nappi RE et al. Migraine is a risk factor for hypertensive disorders in pregnancy: a prospective cohort study. Cephalalgia 2009; 29:286-92. http://dx.doi.org//0.I I I //j. I468-2982.2008.0I704.x

26 Somerville B. Estrogen-withdrawal migraine II. Attempted prophylaxis by continuous estradiol administration. Neurology 1975; 25:245-50. http://dx.doi.org/10.12I2/WNL.25.3.245

27 Somerville BW.The role of estradiol withdrawal in the etiology of menstrual migraine. Neurology 1972; 22:355-65. http://dx.doi. org/I0.12I2/WNL.22.4.355

28 Ertresvag JM, Zwart JA, Helde G et al. Headache and transient focal neurological symptoms during pregnancy, a prospective cohort. Acta Neurol Scand 2005; III:233-7. http://dx.doi. org/I0.I I II/j.I600-0404.2005.00350.x

29 Cripe SM, Frederick IO, Qiu C et al. Risk of preterm delivery and hypertensive disorders of pregnancy in relation to maternal co-morbid mood and migraine disorders during pregnancy. Paediatr Perinat Epidemiol 2011; 25:116-23. http://dx.doi. org/I0.1III/j.1365-3016.2010.01I82.x

30 James $\mathrm{AH}$, Bushnell CD, Jamison MG et al. Incidence and risk factors for stroke in pregnancy and the puerperium. Obstet Gynecol 2005; 106:509-16. http://dx.doi.org/I0.I097/0I.AOG.0000 I72428.784I I.b0

3 I Sztajzel R, Genoud D, Roth S et al. Patent foramen ovale, a possible cause of symptomatic migraine: a study of 74 patients with acute ischemic stroke. Cerebrovasc Dis 2002; 13:102-6. http://dx.doi. org/10.II59/000047758

32 Rasmussen BK. Migraine and tension-type headache in a general population: precipitating factors, female hormones, sleep pattern and relation to lifestyle. Pain 1993; 53:65-72. http://dx.doi. org/10.1016/0304-3959(93)90057-V

33 Nestoriuc Y, Rief W, Martin A. Meta-analysis of biofeedback for tension-type headache: efficacy, specificity, and treatment moderators. J Consult Clin Psychol 2008; 76:379-96. http://dx.doi. org/10.1037/0022-006X.76.3.379

34 Linde K, Allais G, Brinkhaus B et al. Acupuncture for tension-type headache. Cochrane Database Syst Rev 2009; I:CD007587.

35 Linde K, Allais G, Brinkhaus B et al. Acupuncture for migraine prophylaxis. Cochrane Database Syst Rev 2009; I:CD001218.

36 Olesen C, Steffensen FH, Sorensen HT et al. Pregnancy outcome following prescription for sumatriptan. Headache 2000; 40:20-4. http://dx.doi.org/I0.I046/j. I526-46/ 0.2000.00003.x

37 Holland S, Silberstein SD, Freitag F et al. Evidence-based guideline update: NSAIDs and other complementary treatments for episodic migraine prevention in adults: report of the Quality Standards Subcommittee of the American Academy of Neurology and the American Headache Society. Neurology 2012; 78:1346-53. http://dx.doi.org/10.12/2/WNL.0b013e3182535d0c

38 EURAP Study Group. Seizure control and treatment in pregnancy: observations from the EURAP epilepsy pregnancy registry. Neurology 2006; 66:354-60. http://dx.doi.org/I0.12/2/0I. wnl.0000I95888.5I845.80

39 Cantwell R, Clutton-Brock T, Cooper G et al. Saving mothers' lives: reviewing maternal deaths to make motherhood safer: 2006-2008. The eighth report of the confidential enquiries into maternal deaths in the United Kingdom. BJOG 201I; II8:I-203. http://dx.doi. org/I0.I I I I/j. I47/ -0528.20I0.02847.x

40 Bardy A. Seizure frequency in epileptic women during pregnancy and the pueperium: results of the prospective Helskinki study. In: Hanz D, Bossi L, Dam M et al, editors. Epilepsy, pregnancy, and the child. New York: Raven Press; 1982. p.27-37.

4I BassiV.Epilepsy. In: Hainline B, Devinsky O. Neurological complications of pregnancy. Philadelphia: Lippincott, Williams \& Wilkins; 2002.

42 Tomson T, Battino D. Teratogenic effects of antiepileptic drugs. Lancet Neurol 2012; II:803-13. http://dx.doi.org/I0.10I6/SI4744422(I2)70103-5 
43 Sabers A. Algorithm for lamotrigine dose adjustment before, during, and after pregnancy. Acta Neurol Scand 20I2; I26:el-4. http://dx.doi.org/I0.1 III/j.1600-0404.201 I.01627.x

44 Sibai B, Dekker G, Kupferminc M. Pre-eclampsia. Lancet 2005; 365:785-99.

45 Kaplan P. Neurological aspects of eclampsia, In: Hainline B, Devinsky O. Neurological complications of pregnancy. Philadelphia: Lippincott, Williams \& Wilkins; 2002.

46 Nelson-Piercy C. Handbook of obstetric medicine. London: Informa HealthCare; 2006.

47 Liang CC, Chang SD, Lai SL et al. Stroke complicating pregnancy and the puerperium. Eur J Neurol 2006; 13:I256-60. http://dx.doi. org/I0.1III/j.|I468-I33I.2006.0I490.x

48 Wiebers DO,Whisnant JP.The incidence of stroke among pregnant women in Rochester, Minn, 1955 through 1979. JAMA 1985; 254:3055-7. http://dx.doi.org/I0.I00 I/jama. I 985.033602I007/032

49 Sharshar T, Lamy C, Mas JL. Incidence and causes of strokes associated with pregnancy and puerperium. A study in public hospitals of lle de France. Stroke 1995; 26:930-6. http://dx.doi. org/I0.II6I/0I.STR.26.6.930

50 Scott CA, Bewley S, Rudd A et al. Incidence, risk factors, management, and outcomes of stroke in pregnancy. Obstet Gynecol 20 I 2; 120:3 I824. http://dx.doi.org/I0.I097/AOG.0b0 I 3e31825f287c

$5 \mathrm{I}$ Kuklina EV,Tong $X$, Bansil $P$ et al.Trends in pregnancy hospitalizations that included a stroke in the United States from 1994 to 2007 reasons for concern? Stroke 20II; 42:2564-70. http://dx.doi. org/I0.II6I/STROKEAHA.II0.6I0592

52 Rothwell PM, Coull AJ, Giles MF et al. Change in stroke incidence, mortality, case-fatality, severity, and risk factors in Oxfordshire, UK from 1981 to 2004 (Oxford Vascular Study). Lancet 2004; 363:I925-33. http://dx.doi.org/I0.10 I6/S0|40-6736(04) I6405-2
53 Ogilvy CS, Stieg PE, Awad I et al. Recommendations for the management of intracranial arteriovenous malformations: a statement for healthcare professionals from a special writing group of the Stroke Council, American Stroke Association. Circulation 200 I; 103:2644-57. http://dx.doi.org/ I0.I I6I/0I.CIR.I03.2I.2644

54 Gross BA, Du R. Hemorrhage from arteriovenous malformations during pregnancy. Neurosurgery 2012; 7I:349-55; discussion 55-6. http://dx.doi.org//0.1227/NEU.0b013e318256c34b

55 Bates SM, Greer IA, Pabinger I et al. Venous thromboembolism, thrombophilia, antithrombotic therapy, and pregnancy: American College of Chest Physicians evidence-based clinical practice guidelines (8th edition). Chest 2008; 133:844S-86S.

56 Lanska DJ, Kryscio RJ. Risk factors for peripartum and postpartum stroke and intracranial venous thrombosis. Stroke 2000; $31: 1274$ 82. http://dx.doi.org/I0.II6I/0I.STR.3I.6.I274

57 Nelson-Piercy C. Handbook of obstetric medicine. 3rd ed. London Informa Healthcare; 2010. p. 193.

58 Padua L, Di Pasquale A, Pazzaglia C et al. Systematic review of pregnancy related carpal tunnel syndrome. Muscle Nerve 2010; 42:697-702.

59 Donaldson J. Neurology of pregnancy. Philadelphia: WB Saunders; 1989.

60 Katz A, Sergienko R, Dior U et al. Bell's palsy during pregnancy: is it associated with adverse perinatal outcome? Laryngoscope $201 \mathrm{I}$; 121:1935-8;

6 I Hilsinger RL Jr,Adour KK, Doty HE. Idiopathic facial paralysis, pregnancy, and the menstrual cycle. Ann Otol Rhinol Laryngol 1975; 84:433-42.

62 Salinas RA, Alvarez G, Daly F et al. Corticosteroids for Bell's palsy (idiopathic facial paralysis). Cochrane Database Syst Rev 2010; 3:CD001942.

\section{SENIOR FELLOWS' CLUB PRIZE}

The Senior Fellow's Club Prize for 2012 has been won by DMWood and colleagues for their paper on 'Intravenous fluid use in the acutely unwell adult medical inpatient: improving practice through a clinical audit process'. This can be read in issue 32012 at http://www.rcpe.ac.uk/journal/issue/journal_42_3/wood.pdf

A prize of $£ 250$ will be awarded to the first-named (or corresponding) author of an original research paper on a clinical topic, deemed by a panel of judges to be the best paper by a doctor-in-training (i.e. pre-consultant level) published in The Journal of the Royal College of Physicians of Edinburgh in 2013.The best paper will be selected by a panel of judges, including a senior Fellow, an active clinician and a member of the editorial team.

Further details may be obtained from the Editorial Office, RCPE, 9 Queen Street, Edinburgh, EH2 IJQ, tel 013। 2473652 or email editorial@rcpe.ac.uk. 